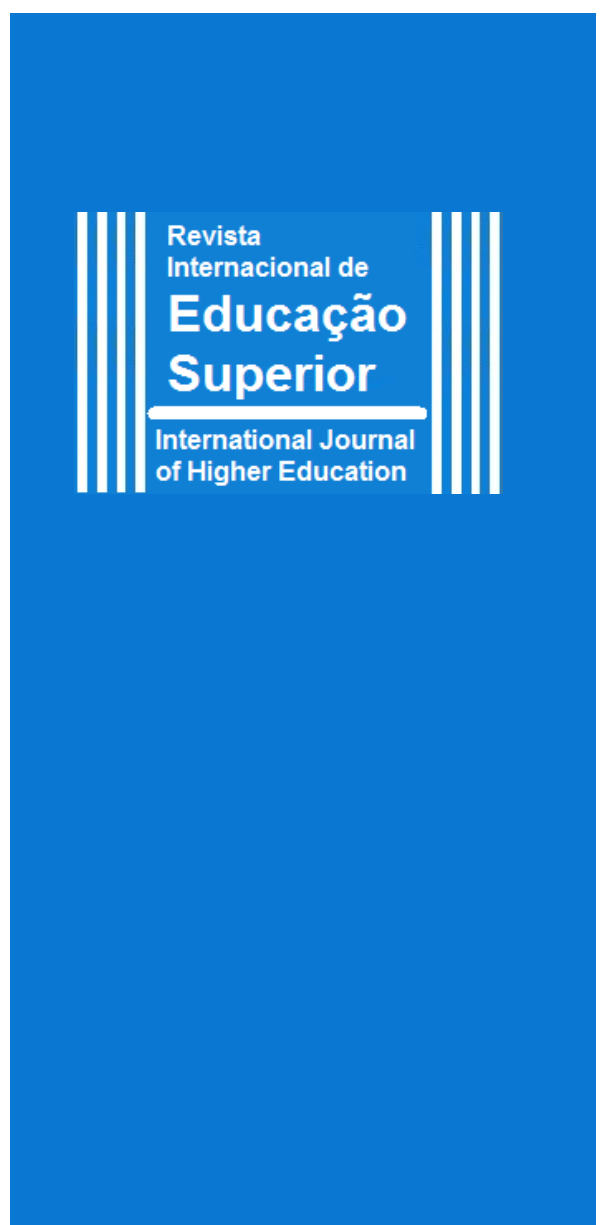

Os Editores

Gildenir Carolino Santos

José Camilo dos Santos Filho

Maria de Lourdes Pinto de Almeida

Publicado: 28 maio 2019

dois $10.20396 /$ riesup.v5i0.8655522 e-location: e019046

ISSN 2446-9424

Checagem Antiplagiarismo turnitin

Distribuido sobre

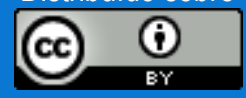

\section{Internacionalização da Educação Superior no} território Iberoamericano

Desde a entrada da Internet no universo da editoração eletrônica, um novo método de publicação online foi criado com a intenção de facilitar os processos editoriais e de publicações, além de dar uma maior visibilidade dos artigos publicados.

Criado há certo tempo no continente europeu, e agora ganhando espaço nas Américas, esse método é chamado de publicação contínua (rolling pass), ou simplesmente PC, que é a publicação dos artigos em um único volume sem pausas periódicas, sem a espera do fechamento de um número para publicar outro, o que pode diminuir a visibilidade dos artigos, e ganhando mais impacto na consulta e citações dos artigos. (RODRIGUES; SANTOS, 2019).

Assim, desde setembro de 2018, a Revista Internacional de Educação Superior - RIESUP, adota essa modalidade para fortalecer e melhorar aceleradamente o desenvolvimento da publicação do Grupo de Pesquisa GIEPES da Faculdade de Educação da Universidade Estadual de Campinas em parceria com a Rede Iberoamericana de Estudos e Pesquisas em Políticas e Processos de Educação Superior - RIEPPES - Universidade do Oeste de Santa Catarinense, tendo como missão socializar a produção de estudos e pesquisas científicas, de caráter teórico ou empírico, na área da educação superior. (SANTOS FILHO; ALMEIDA; SANTOS, 2019).

Socializar a produção de estudos e pesquisas científicas da área da educação superior é o que mais queremos na editoria da RIESUP, e, portanto, a entrada da modalidade de publicação contínua veio ao encontro dessa necessidade fazendo-se cumprir essa missão no âmbito do nosso periódico. Além disso, a RIESUP é uma das únicas publicações da área da Educação a ser publicada em 02 (dois) idiomas: português e inglês, quando também às vezes o inglês é substituído pelo espanhol. Podemos afirmar que a barreira do idioma não é nenhum empecilho para o desbravamento da Revista entre fronteiras. 
Dessa forma, a edição do volume da publicação contínua de 2019 iniciada em setembro de 2018, encerra seu volume em maio de 2019, com 36 (trinta e seis) artigos originais, sendo 11 (onze) deles destinados ao dossiê "Internacionalização da Educação Superior no território Iberoamericano" 3 (três) artigos de pesquisa; 3 (três) relatos de experiência e 3 (três) resenhas, totalizando a coleção de 45 (quarenta e cinco) documentos inéditos sobre a temática da educação superior. Com isso, todos os editoriais a partir deste, serão lançados no final da conclusão de cada volume relatando o conteúdo e a essência da temática a ser tratada no decorrente volume.

Iniciamos este volume da RIESUP, com Seção Dossiê, intitulada "Internacionalização da Educação Superior no território Iberoamericano", que estão mais descritivos na Apresentação elaborada por Elisabete Monteiro de Aguiar Pereira e Maria de Lourdes Pinto de Almeida com os seguintes trabalhos:

1. Marcio Giusti Trevisol (Universidade do Oeste de Santa Catarina) e Altair Alberto Fávero (Universidade de Passo Fundo) - As diversas faces da internacionalização: análise comparativa entre duas instituições comunitárias do sul do Brasil;

2. Maria Cristina Parra-Sandoval (Universidad del Zulia), Marisol Fucci Bornachera (Universidad del Zulia), Ana Julia Romero Gonzalez (Universidad del Zulia) - La inserción de la Universidad del Zulia en el proceso de internacionalización de la educación superior;

3. Fernanda Geremias Leal (Universidade do Estado de Santa Catarina), María Soledad Oregioni (Consejo Nacional de Investigaciones Científicas y Técnicas) - Aportes para analizar la internacionalización de la educación superior desde Latinoamérica: un enfoque crítico, reflexivo y decolonial;

4. Pablo Pereira (Universidade Regional de Blumenau), Marcia Regina Selpa Heinzle (Universidade Regional de Blumenau) - A internacionalização das ações de ensino, pesquisa e extensão na Universidade Regional de Blumenau;

5. Carmen Célia Barradas Correia Bastos (Universidade Estadual do Oeste do Paraná), Elenita Conegero Pastor Manchope (Universidade Estadual do Oeste do Paraná), Marta Lucia Alves Assenza (Universidade Estadual do Oeste do Paraná) - A internacionalização da educação superior na Universidade Estadual do Oeste do Paraná - UNIOESTE: da passividade a uma política institucional de internacionalização;

6. Pricila Kohls dos Santos (Pontifícia Universidade Católica do Rio Grande do Sul), Marília Costa Morosini (Pontifícia Universidade Católica do Rio Grande do Sul) Internacionalização e educação para a cidadania global: a visão de professores universitários;

7. Enrique Daniel Andrés Martinez Larrechea (Instituto Universitario Sudamericano), Adriana Chiancone (Universidad Claeh) - El sur global en la educación superior en Uruguay: la Fundación Instituto Universitario Sudamericano; 
8. Margarita Victoria Rodríguez (Universidade Federal do Mato Grosso do Sul), Silvia Helena Brito de Andrade (Universidade Federal de Mato Grosso do Sul), Flávia Melville Paiva (Universidade Federal de Mato Grosso do Sul) - O processo de internacionalização na/da Universidade Federal de Mato Grosso do Sul (UFMS) Brasil;

9. Elisabete Monteiro de Aguiar Pereira (Universidade Estadual de Campinas) Internacionalização na universidade contemporânea: uma visão da internacionalização em uma Universidade Pública Paulista;

10. Silvia Regina Canan, Jéssica De Marco, Thais Campos da Silva (Universidade Regional Integrada do Alto Uruguai e das Missões) - Processos de internacionalização: conquistas e desafios no contexto da URI - Universidade comunitária;

11. Pablo Daniel Garcia, Julieta Claverie, Norberto Rafael Fernández Lamarra (Universidad Nacional de Tres de Febrero) - Políticas de internacionalización de la Educación Superior en la Argentina: La promoción de la Universidad en el exterior.

Além deste Dossiê, em meados de agosto de 2018, a RIESUP tornou pública uma chamada para coleta de artigos para compor uma edição temática juntamente com os artigos de fluxo contínuo, voltada para "A educação superior e a Reforma de 1918 de Córdoba", justamente em virtude da comemoração dos 100 anos da Reforma de Córdoba.

A Reforma Universitária de Córdoba de 1918, na Argentina, é considerada um marco na história mundial do Ensino Superior, mas principalmente na defesa da democratização deste nível de ensino na América Latina e no Caribe. O manifesto, encabeçado pelos estudantes da Universidade de Córdoba intitulado La juventud argentina de Córdoba a los hombres libres de Sud América Manifiesto de la Federación Universitaria de Córdoba 1918, é considerado por muitos uma antecipação do que representou o maio francês de 1968, que teve objetivos similares.

Deste modo, esta coletânea de artigos se propõe a discutir, no centenário da Reforma de 1918 de Córdoba, suas implicações a partir dos eixos relacionados à ementa que esta temática propõe: Estudos e pesquisas relacionados aos desafios da educação superior, as políticas da educação superior dos diferentes países, sua avaliação, regulação, processos e os diferentes atores desse contexto.

Assim, obtivemos para a construção desta temática seis (6) trabalhos que narram justamente esse ponto de vista dos 100 anos da Reforma, com trabalhos que se configuram na Seção Artigos, juntamente com os demais artigos do fluxo contínuo, a saber:

1. Entre Córdoba e Bolonha: o REUNI e a contraditória expansão da universidade brasileira - Lavoisier Almeida dos Santos e Valci Melo analisam o processo de expansão recente da educação superior brasileira em seu movimento contraditório de massificação do acesso e de precarização das instituições públicas. Para tal, investiga, à luz do materialismo histórico-dialético, o Programa de Apoio a Planos de Reestruturação e Expansão das Universidades Federais (REUNI). Ao longo do texto, demonstra-se que, embora o Reuni garanta o acesso à educação superior a alunos pertencentes às classes mais pobres da sociedade brasileira, ele o faz submetendo-se

\begin{tabular}{l|l|l|l|l|l} 
(c) Rev. Inter. Educ. Sup. & Campinas, SP & v.5 & $1-13$ & e019046 & 2019
\end{tabular} 
às exigências do capital internacional e à sua lógica de aligeiramento e empobrecimento da formação acadêmica. Por fim, conclui-se que, ainda que não se possa negar que o Reuni intensifica o movimento de expansão da educação superior no Brasil - e, nesse ponto, aproxima-se do legado de Córdoba -, ele está mais próximo do chamado Processo de Bolonha e da consequente mercantilização do serviço educacional.

2. A Reforma de Córdoba e a educação superior: institucionalização da extensão universitária no Brasil - Simone da Rosa Messina Gomez, Marilene Gabriel Dalla Corte e Gabriela Paim Rosso (todas da Universidade Federal de Santa Maria) relatam que a Reforma de Córdoba (1918) estabeleceu um marco para as universidades latinoamericanas constituindo-se como uma referência para suas reformas universitárias. Entre os princípios que nortearam essa manifestação estudantil, está a extensão universitária, entendida como compromisso social da universidade. Nessa perspectiva, as autoras objetivam-se analisar os reflexos da Reforma de Córdoba com relação à extensão universitária no contexto brasileiro.

3. Reforma universitária de Córdoba: impactos na América Latina e lições para o tempo presente - Jórissa Danilla Nascimento Aguiar e Gonzalo Ádrian Rojas (ambos da Universidade Federal de Campina Grande) trazem ao debate da comemoração dos 100 anos da Reforma de Córdoba, a importância de estudar essa experiência de rebelião contra a hierarquia universitária, ao passo que destacam também sua atualidade, principalmente no que diz respeito à necessidade de democratização da universidade $\mathrm{e}$ sua vinculação a classe trabalhadora e setores populares. Os autores objetivam contribuir para que essa experiência seja conhecida pela ampla maioria dos estudantes no Brasil, indicando também sua relevância para (re)construir um novo movimento estudantil numa perspectiva emancipadora.

4. A Reforma de Córdoba de 1918: estado do conhecimento baseado em artigos científicos (1978-2018) - Marcelo Innocentini Hayashi e Maria Cristina Piumbato Innocentini Hayashi (ambos da Universidade Federal de São Carlos) no âmbito do marco do centenário da Reforma de Córdoba, investigaram como se configura a produção científica sobre a reforma universitária e apresenta um balanço das pesquisas que analisaram desde o significado desse movimento ocorrido na Argentina em 1918, até seus e impactos e projeção futura no contexto das universidades da América Latina e do Caribe. Como caracterizado por um estudo exploratório e descritivo, os autores tiveram como objeto de estudo artigos científicos $(n=90)$ disponíveis em bases de dados de acesso aberto publicados em periódicos científicos $(n=47)$ de diferentes países $(n=13)$ no período entre 1978 e 2018.

5. As ações afirmativas na base da democratização da educação superior brasileira: irradiações da Reforma Universitária de Córdoba - Schirlei Russi von Dentz, Silvana Rodrigues de Souza Sato e Ione Ribeiro Valle (Universidade Federal de Santa Catarina) contextualizam a proposta da Reforma de Córdoba e coloca em pauta o surgimento das ações afirmativas em diferentes países e para fins variados. Denomina o que é uma ação afirmativa e demonstra como o programa e, posteriormente, a política de ações afirmativas foram se constituindo e sendo adotados nas universidades brasileiras, particularmente na Universidade Federal de Santa Catarina (UFSC). 
6. A importância da Reforma de Córdoba para o contexto acadêmico latino-americano: cem anos de contribuição - Elisabete Monteiro de Aguiar Pereira (Universidade Estadual de Campinas) apresenta os contextos social, político, econômico e educacional do movimento de Córdoba de 1918. Analisa esses contextos no seu desenvolvimento histórico como bastidores da eclosão da reforma de Córdoba e publicação do documento conhecido como Manifesto Liminar, ou documento da Reforma Universitária de Córdoba. O ponto central do artigo é o de analisar a importância que o movimento teve naquele tempo e as razões da sua influência permanente nos movimentos estudantis nestas dez décadas de existência, em vários países da América Latina, tornando-se um importante legado para os estudantes e um igualmente importante chamado para a organização particular de uma universidade latino-americana com olhar para suas específicas questões sociais, culturais e educacionais.

$\mathrm{Na}$ sequência com os textos de fluxo contínuo, tivemos o trabalho Análise da internacionalização da educação superior entre países emergentes: estudo de caso do Brasil com os demais países membros dos BRICS, de autoria de Larissa Cristina Dal Piva Moreira e Sonia Maria Ranincheski (ambas da Universidade Federal do Rio Grande do Sul). O artigo tem como $\mathrm{O}$ objetivo geral analisar o processo de internacionalização universitária do Brasil com os demais países membros dos BRICS - Rússia, Índia, China e África do Sul comparando as políticas adotadas durante o período de governo de Luiz Inácio Lula da Silva (2003-2010) e Dilma Rousseff (2011-2016).

Em Ensino de probabilidade e estatística por meio da análise exploratória de dados e resolução de problemas, Fabiano dos Santos Souza (Universidade Federal Fluminense) se baseia em estudos, pesquisas e reflexões de um grupo de pesquisa de Ensino e Aprendizagem em Matemática e Estatística, os quais foram convertidos em uma proposta metodológica para o ensino de probabilidade e estatística implementada numa oficina ministrada no III Dia da Matemática do Laboratório de Educação Matemática (LABEM) de uma Universidade Federal. No estudo participaram 24 sujeitos do curso de licenciatura em Matemática, com objetivo de avaliar a proposta em relação ao processo de ensino e aprendizagem dos conteúdos básicos de estatística e probabilidade. Os objetivos principais desta oficina foram: identificar a Estatística como sendo uma poderosa ferramenta para análise de dados, que pode ser utilizada de forma a equilibrar técnicas e conceitos e proporcionar aos participantes um espaço de reflexão para a construção de um trabalho coletivo, que interligue saberes acadêmicos e práticos.

No trabalho sobre a Auto(trans)formação permanente e desenvolvimento docente no contexto do PIBID, resultado de uma pesquisa de doutorado concluída em 2017, os autores Maria Rosângela Silveira Ramos (Instituto Federal de Educação Ciência e Tecnologia Farroupilha), Celso Ilgo Henz (Universidade Federal de Santa Maria) e Dóris Pires Vargas Bolzan (Universidade Federal de Santa Maria) tiveram como objetivo compreender e analisar a realização e os desdobramentos formativos do Programa Institucional de Bolsa de Iniciação à Docência (PIBID), nos subprojetos de Química e Biologia em uma Instituição de Ensino Superior.

No trabalho sobre $O$ departamento de desenho da UFPR e o ensino na graduação como definidor da sua trajetória (1974-1993), de Rossano Silva, Adriana Vaz e Emilio Eiji Kavamura (Universidade Federal do Paraná), o artigo focaliza o grupo de professores e a estrutura de ensino de graduação do Departamento de Desenho (DDES) da Universidade

\begin{tabular}{l|l|l|l|l|l|}
\hline (c) Rev. Inter. Educ. Sup. & Campinas, SP & v.5 & $1-13$ & e019046 & 2019
\end{tabular}


Federal do Paraná no período de 1974 a 1993, quando as atividades de extensão e pesquisa eram esporádicas e consequentemente parte dos elementos do estudo da trajetória dessa unidade administrativa girava em torno da estruturação das disciplinas e da capacitação do corpo docente. Buscam como como aportes teóricos a teoria praxiológica e o conceito de trajetória de Pierre Bourdieu e a ideia de configuração de Norbert Elias, no entendimento de que a história dessa instituição de ensino superior se conforma pela posição dos seus agentes dentro do campo universitário, que representa o microuniverso do Setor de Ciências Exatas.

Jorge Santa Anna (Universidade Federal do Espírito Santo) no trabalho sobre as Potencialidades das visitas técnicas na docência universitária: aplicações nas disciplinas de representação da informação, aborda o potencial das visitas técnicas, consideradas como métodos inovadores de ensino, e os reflexos por elas promovidos quando aplicadas em disciplinas de cunho técnico-operacional, no Curso Superior de Biblioteconomia. Também apresenta fundamentos teóricos sobre docência universitária, algumas características das visitas técnicas e reflexões a respeito do ensino superior de Biblioteconomia - com foco nas disciplinas de Representação documentária.

Em Docência na educação a distância: abordagem sobre o perfil profissional, Andrea Karla Ferreira Nunes (Universidade Tiradentes), Alice Virginia Brito de Oliveira (Universidade Tiradentes) e Rosimeri Ferraz Sabino (Universidade Federal de Sergipe) tiveram como objetivo delimitar os elementos distintivos da representação docente para a educação a distância, a partir da análise da legislação sobre a formação docente e do conceito de polidocência.

No artigo seguinte Diogo Hiroshi Beçon Kussakawa, Clesio Acilino Antonio e Ângela Maria Silveira Portelinha (todas da Universidade Estadual do Oeste do Paraná) abordam sobre As contribuições das Diretrizes Curriculares Nacionais de 2001 aos projetos político-pedagógicos dos cursos de Medicina do Brasil. O estudo volta-se à educação médica, ao estudar o caso do projetos político-pedagógicos (PPP) do curso de Medicina da Universidade Estadual do Oeste do Paraná, no campus de Francisco Beltrão (PPPMFB) e correlacioná-lo com as DCN2001. Teve como objetivo é evidenciar a forma como o PPPMFB foi constituído a partir dos elementos integrantes de uma nova educação médica sugeridos pelas DCN2001.

Maria Angélica Pedra Minhoto e Isabel Melero Bello (ambas da Universidade Federal de São Paulo), com o trabalha A política de reestruturação das universidades federais e a instituição de modelos formativos inovadores: a UNIFESP em análise analisam os diferentes modelos formativos da Unifesp a fim de compreender em que medida favorecem a permanência e a conclusão de seus estudantes. Para tanto, foram analisados dados referentes à matrícula, coeficiente de rendimento, taxa de evasão e taxa de sucesso acadêmico nos diferentes modelos formativos. A análise mostra que modelos alternativos por si sós não ampliam a permanência e a conclusão e não melhoram os rendimentos acadêmicos dos estudantes, inclusive nos bacharelados interdisciplinares.

Com trabalho sobre $O$ modelo católico de ensino superior no Brasil: Padre Leonel Franca e a criação da Pontifícia Universidade Católica - PUC, os autores Natália Cristina Oliveira, Névio de Campos e Oriomar Skalinski Júnior (todos da Universidade Estadual de Maringá), têm como o objetivo neste artigo discutir a implantação do modelo católico de formação no Ensino Superior brasileiro. Desta forma, os autores destacam o papel \begin{tabular}{|l|l|l|l|l|l|}
\hline (c) Rev. Inter. Educ. Sup. & Campinas, SP & v.5 & $1-13$ & e019046 & 2019
\end{tabular} 
desempenhado pelo padre jesuíta Leonel Edgard da Silveira Franca (1893-1948), liderança intelectual responsável pela articulação e viabilização institucional da Pontifícia Universidade Católica (PUC) do Rio de Janeiro. Para tanto, discutem como o jesuíta trabalhou junto à sua rede de sociabilidade para viabilizar a criação do Instituto Católico de Estudos Superiores, em 1932; em seguida, como essa ação foi aprimorada com a criação das Faculdades Católicas, em 1941; e, por fim, como o objetivo da militância católica foi alcançado, com a fundação da PUC, em 1948, da qual Leonel Franca se tornou reitor.

No artigo sobre a A prática pedagógica colaborativa: pesquisa-ação em um curso de administração, Sofia Maria de Araújo Ruiz (Universidade Federal do Mato Grosso) e Raimunda Abou Gebran (Universidade do Oeste Paulista) apresentam o processo e os resultados de uma pesquisa-ação colaborativa com docentes do Curso de Administração de uma universidade pública. As autoras analisam a prática pedagógica colaborativa na educação superior, investigando suas dificuldades/limitações e seus avanços, bem como o contexto no qual ela ocorre.

Gracy Kelly Andrade Pignata Oliveira e Susana Couto Pimentel (ambas da Universidade Federal do Recôncavo da Bahia) apresentam o trabalho sobre a Inclusão na educação superior: apontamentos sobre a afiliação de universitários com deficiência. $\mathrm{O}$ artigo vincula-se a uma pesquisa cujo objetivo foi compreender a trajetória de afiliação de estudantes com deficiência na Educação Superior.

No trabalho Formação profissional e CTS: uma abordagem dos institutos federais, Sidney Reinaldo Silva e Rodrigo Rafael Fernandes (ambos do Instituto Federal do Paraná), abordam os princípios da formação profissional dos Institutos federais (IFs) e sua correlação com a abordagem Ciência Tecnologia e Sociedade (CTS). Os autores mostram como os IFS contribuem para pensar a formação profissional na perspectiva CTS, isto é, de forma socialmente engajada.

Na sequência temos o trabalho de Roseli Zen Cerny, Marina Bazzo de Espíndola, Graziela Gomes Stein e Julia Maria Gerhardt da Rocha (todos da Universidade Federal de Santa Catarina), intitulado Formação para a integração das TDIC ao currículo: contribuição da docência em cursos lato sensu para a formação inicial. Os autores analisam se a vivência de docentes universitários como professores do Curso EECD favoreceu a incorporação da discussão sobre a integração das Tecnologias Digitais de Informação e Comunicação (TDIC) nos cursos de licenciatura em que atuam, visando a integração das tecnologias ao currículo, ofertado na modalidade a distância.

Estefanni Mairla Alves e Ruth Maria de Paula Gonçalves (ambas da Universidade Estadual do Ceará) com o trabalho sobre Educação como mercadoria: desafios da educação superior em meio ao capitalismo em crise têm como objetivo analisar e discutir esse processo por meio de uma revisão bibliográfica que resgata como o ensino superior, em especial a universidade pública, tem passado por um longo processo de deixar de ser direito para se tornar uma mercadoria especulada no mercado financeiro.

Em Mudanças e continuidades dos marcos legais do curso de pedagogia no Brasil, Andressa Graziele Brandt (Instituto Federal Catarinense) e Márcia de Souza Hobold (Universidade Federal de Santa Catarina) analisam os quatro marcos legais do curso de Pedagogia no Brasil, no que se refere às mudanças e continuidades acerca dos currículos para a formação de professores.

\begin{tabular}{l|l|l|l|l|l}
\hline (c) Rev. Inter. Educ. Sup. & Campinas, SP & v.5 & $1-13$ & e019046 & 2019
\end{tabular}


Solange Riato Prates e Josiane Peres Gonçalves (ambas da Universidade Federal de Mato Grosso do Sul) no trabalho intitulado Educação superior e relações de gênero: atividades domiciliares para mães estudantes de pedagogia investigam a realidade de mulheres que se tornaram mães enquanto cursavam Pedagogia, com ênfase para os desafios vivenciados por elas ao conciliar os estudos com a maternidade, bem como a postura da universidade em relação às atividades domiciliares e atendimento a essas alunas.

Dando sequência na apresentação dos artigos, Ana Paula Barbieri de Mello e Edite Maria Sudbrack (ambas da Universidade Regional Integrada do Alto Uruguai e das Missões) no trabalho Caminhos da educação infantil: da constituição de 1988 até a BNCC, baseado na dissertação de mestrado da primeira autora, expõem e discutem os principais pareceres e princípios dos documentos legais desde a Constituição Federal de 1988 até a BNCC para a Educação Infantil, com o intuito de compreender a contribuição de cada documento para as Políticas de Educação Infantil.

Roque Strieder (Universidade do Oeste de Santa Catarina) no seu trabalho sobre Democracia e educação: desafiando a lógica tecnicista e utilitarista, o autor contextualiza o cenário onde os espaços acadêmicos e de formação humanizadora, gradativamente diminuem seus enfoques pedagógicos e formativos e, substituídos pela gestão e pelas competências, perdem sua dimensão intelectual, reflexiva criativa e humanizadora. Ele entende que todo e qualquer esforço e exercício que problematiza o ideal globalizador da formação humana, envolve e integra um complexo contexto de demandas e desafios contemporâneos. Dentre eles, o autor situa o desafio de resistência política à essa proposição formalizadora dos mecanismos da lógica educacional priorizando a instrumentalização, o utilitarismo e a sedimentação da obediência.

Em $O$ direito à educação no ensino superior de pessoas com deficiências, Geane de Oliveira Januário (Universidade Federal do Paraná), realizou-se uma revisão sistemática, com o intuito de levantar os trabalhos que abordam a temática sobre Educação Superior, tomando como fontes de pesquisas o catálogo de teses e dissertações da Capes, a Biblioteca Digital Brasileira de Teses e Dissertações, os periódicos científicos nas bases SciELO e Portal de Periódicos da Capes, além da Revista Internacional de Educação Superior.

Na Seção Artigos de Pesquisas, apresentamos três (3) trabalhos, sendo o primeiro deles intitulado Busca dos fatores associados à evasão: um estudo de caso no campus universitário da UFC em Crateús, de autoria de Carlos Henrique Mendes de Oliveira, Francisco Raul Teixeira Santos, Janaina Lopes Leitinho e Luisa Gardênia Alves Tomé Farias (Universidade Federal do Ceará) realizaram uma pesquisa com 63 estudantes evadidos do campus Crateús da Universidade Federal do Ceará (UFC) no intuito de analisar as causas da evasão por meio de uma análise fatorial exploratória e de uma confirmatória.

Raimunda Maria da Cunha Ribeiro (Universidade Estadual do Piauí) com o trabalho sobre As bases institucionais da política de extensão universitária: entendendo as propostas de universidades federais nos planos de desenvolvimento institucional, a autora analisa a política de extensão de universidades públicas federais, tendo como base as orientações declaradas nos Planos de Desenvolvimento Institucional.

Na última pesquisa temos o Desempenho acadêmico em cálculo diferencial e integral: um estudo de caso, dos autores Chaiane de Medeiros Rosa, Karly Barbosa Alvarenga e

\begin{tabular}{|l|l|l|l|l|l|}
\hline C Rev. Inter. Educ. Sup. & Campinas, SP & v.5 & $1-13$ & $\mathrm{e} 019046$ & 2019 \\
\hline
\end{tabular}


Fabiano Fortunato Teixeira dos Santos (Universidade Federal de Goiás). Este trabalho é parte de uma investigação que objetiva conhecer a história do conjunto de disciplinas que estudam os conteúdos de Cálculo Diferencial e Integral ministradas na Universidade Federal de Goiás. Este artigo analisa o rendimento acadêmico dos alunos na disciplina Cálculo $1 \mathrm{~A}$ da referida instituição, do primeiro semestre de 2010 ao segundo semestre de 2016, o que corresponde a 14 semestres letivos, verificando aspectos como: alunos matriculados, aprovação e reprovação e médias finais.

Na Seção Relato de experiências, temos três (3) trabalhos. No primeiro deles, Roberta Ekuni (Universidade Estadual do Norte do Paraná) nos brinda com o trabalho Internacionalização via doutorado sanduíche: relato de experiência no país da ciência, que tem como objetivo relatar um estágio de doutorado realizado na Washington University in Saint Louis, focando nas atividades de pesquisa, ensino e extensão.

No relato de experiência seguinte, trazemos a contribuição: Estratégias para motivar a aprendizagem da embriologia: um relato de experiência no curso de enfermagem da Universidade Federal do Rio Grande do Sul, de autoria de Simone Marcuzzo, Paola Melo Campos, Júlia Schneider e Claudenilson da Costa Régis (todos da Universidade Federal do Rio Grande do Sul), visando apresentar a experiência da utilização de metodologias ativas no curso de Enfermagem com o intuito de tornar mais significativo o aprendizado da Embriologia. Essa investigação-ação teve como objetivos: 1) relacionar conteúdos básicos teóricos com as práticas disciplinares e 2) envolver a atenção do aluno com o conteúdo desenvolvido na sala de aula.

No último relato, as autoras Nathália Cristina Amorim Tamaio de Souza (Universidade Estadual de Campinas) e Flávia Graziela Moreira Passalacqua (Universidade Estadual Paulista), com o trabalho sobre $O$ processo de construção da profissionalidade docente: aspectos concernentes à formação inicial, relatam a partir de experiências e registros coletados ao longo de atividades de ensino ministradas a duas turmas do quarto ano do curso de Pedagogia de uma universidade do interior paulista. O objetivo do trabalho teve como provocar reflexões sobre os aspectos da profissionalidade docente que se desenvolvem, ou deveriam se desenvolver, no âmbito da formação inicial de professores.

Para finalizar na última seção da RIESUP, a Seção Resenhas, contribui com três resenhas, a saber:

1. Interfaces das políticas educacionais sobre a produção científica e formação de pesquisadores na América Latina - Evandro Consaltér e Altair Alberto Fávero (ambos da Universidade de Passo Fundo). O presente texto constitui-se em uma resenha do livro "Produção do Conhecimento Científico e Formação do Pesquisador na América Latina: as investigações de políticas educacionais em xeque", publicado pela editora Mercado de Letras, em dezembro de 2017. A obra em questão reúne textos de pesquisadores do Brasil, Chile, México e Espanha. A coletânea oferece uma rica e importante contribuição para a discussão dos rumos das políticas de formação de pesquisadores e da produção do conhecimento na área das políticas educacionais.

2. Da universidade à commoditycidade: ou de como e quando, se a educação/formação é sacrificada no altar do mercado, o futuro da universidade se situaria em algum lugar do passado - Fernanda de Aragão Mikolaiczyk (Universidade Federal de Santa 
Catarina). As discussões postas para debate na obra objeto desta resenha - Da universidade à commoditycidade: ou de como e quando, se a educação/formação é sacrificada no altar do mercado, o futuro da universidade se situaria em algum lugar do passado -, de autoria de Lucídio Bianchetti e Valdemar Sguissardi, situam o leitor quanto ao projeto de classe burguês que a domina, materializado nas formas mercantis que a atingem.

3. Educação superior como bem público perspectivas para o centenário da Reforma de Córdoba - Emanuella Scoz (Universidade Regional de Blumenau). Este texto é uma resenha crítica da obra de Marco Antonio Rodrigues intitulada Educação Superior como bem público, que evidencia o atual curso do ensino superior no mundo. Nesta obra o autor constrói uma crítica saudosista do ensino superior atual e suas vertentes mercantis, lembrando os conceitos humanistas e libertários contidos no tratado de Córdoba de 1918, e na Conferência Mundial do Ensino Superior de 1998. Análise construída para o evento de comemoração dos 25 anos de criação da AUGM.

Boa leitura!

Campinas, SP, maio de 2019.

\section{Referências}

AGUIAR, J. D. N.; ROJAS, G. ÁDRIAN. Reforma universitária de Córdoba: impactos na América Latina e lições para o tempo presente. Revista Internacional de Educação Superior, v. 5, e019029, 31 jan. 2019. Disponível em: https://periodicos.sbu.unicamp.br/ojs/index.php/riesup/article/view/8653663. Acesso em: 25 maio 2019.

BASTOS, C. C. B. C.; MANCHOPE, E. C. P.; ASSENZA, M. L. A. A internacionalização da educação superior na Universidade Estadual do Oeste do Paraná - UNIOESTE: da passividade a uma política institucional de internacionalização. Revista Internacional de Educação Superior, v. 5, e019039, 19 fev. 2019. Disponível em:

https://periodicos.sbu.unicamp.br/ojs/index.php/riesup/article/view/8653899. Acesso em: 25 maio 2019.

CANAN, S. R.; DE MARCO, J.; SILVA, T. C. DA. Processos de internacionalização: conquistas e desafios no contexto da URI - Universidade comunitária. Revista Internacional de Educação Superior, v. 5, e019044, 1 maio 2019. Disponível em:

https://periodicos.sbu.unicamp.br/ojs/index.php/riesup/article/view/8653862. Acesso em: 25 maio 2019.

DENTZ, S. R. VON; SATO, S. R. DE S.; VALLE, I. R. As ações afirmativas na base da democratização da educação superior brasileira: irradiações da Reforma Universitária de Córdoba. Revista Internacional de Educação Superior, v. 5, e019034, 7 mar. 2019.

Disponível em: https://periodicos.sbu.unicamp.br/ojs/index.php/ riesup/article/view/8653659. Acesso em: 25 maio 2019. 
GARCIA, P. D.; CLAVERIE, J.; FERNÁNDEZ LAMARRA, N. R. Políticas de internacionalización de la Educación Superior en la Argentina: La promoción de la Universidad en el exterior. Revista Internacional de Educação Superior, v. 5, e019045, 1 maio 2019. Disponível em: https://periodicos.sbu.unicamp.br/ojs/index.php/ riesup/article/view/8653861. Acesso em: 25 maio 2019.

HAYASHI, M. I.; HAYASHI, M. C. P. I. A Reforma de Córdoba de 1918: estado do conhecimento baseado em artigos científicos (1978-2018). Revista Internacional de Educação Superior, v. 5, e019033, 16 fev. 2019. Disponível em: https://periodicos.sbu.unicamp.br/ojs/index.php/riesup/article/view/8653658. Acesso em: 25 maio 2019.

KUSSAKAWA, D. H. B.; ANTONIO, C. A.; PORTELINHA, ÂNGELA M. S. As contribuições das Diretrizes Curriculares Nacionais de 2001 aos projetos políticopedagógicos dos cursos de Medicina do Brasil. Revista Internacional de Educação Superior, v. 5, e019012, 3 dez. 2018. Disponível em: https://periodicos.sbu. unicamp.br/ojs/index.php/riesup/article/view/8653495. Acesso em: 25 maio 2019.

LEAL, F. G.; OREGIONI, M. S. Aportes para analizar la internacionalización de la educación superior desde Latinoamérica: un enfoque crítico, reflexivo y decolonial. Revista Internacional de Educação Superior, Campinas, SP, v. 5, e019036, 16 fev. 2019. Disponível em: https://periodicos.sbu.unicamp.br/ojs/index.php/ riesup/article/view/8653635. Acesso em: 25 maio 2019.

MARTINEZ LARRECHEA, E. D. A.; CHIANCONE, A. El sur global en la educación superior en Uruguay: la Fundación Instituto Universitario Sudamericano. Revista Internacional de Educação Superior, v. 5, e019041, 7 mar. 2019. Disponível em: https://periodicos.sbu.unicamp.br/ojs/index.php/riesup/article/view/8653901. Acesso em: 25 maio 2019.

MINHOTO, M. A. P.; BELLO, I. M. A política de reestruturação das universidades federais e a instituição de modelos formativos inovadores: a UNIFESP em análise. Revista

Internacional de Educação Superior, v. 5, e019013, 12 dez. 2018. Disponível em: https://periodicos.sbu.unicamp.br/ojs/index.php/riesup/article/view/8652915. Acesso em: 25 maio 2019.

MOREIRA, L. C. D. P.; RANINCHESKI, S. M. Análise da internacionalização da educação superior entre países emergentes: estudo de caso do Brasil com os demais países membros dos BRICS. Revista Internacional de Educação Superior, v. 5, e019001, 20 set. 2018. Disponível em: https://periodicos.sbu.unicamp.br/ojs/index.php/riesup/article/view/8652804. Acesso em: 25 maio 2019.

NUNES, A. K. F.; OLIVEIRA, A. V. B. DE; SABINO, R. F. Docência na educação a distância: abordagem sobre o perfil profissional. Revista Internacional de Educação Superior, v. 5, e019009, 21 out. 2018. Disponível em: https://periodicos.sbu. unicamp.br/ojs/index.php/riesup/article/view/8653379. Acesso em: 25 maio 2019.

OLIVEIRA, G. K. A. P.; PIMENTEL, S. C. Inclusão na educação superior: apontamentos sobre a afiliação de universitários com deficiência. Revista Internacional de Educação Superior, v. 5, e019017, 18 dez. 2018. Disponível em:

\begin{tabular}{l|c|c|c|c|c|}
\hline (C) Rev. Inter. Educ. Sup. & Campinas, SP & v.5 & $1-13$ & e019046 & 2019 \\
\hline
\end{tabular}


https://periodicos.sbu.unicamp.br/ojs/index.php/riesup/article/view/8653637. Acesso em: 25 maio 2019.

OLIVEIRA, N. C.; CAMPOS, N. DE; SKALINSKI JÚNIOR, O. O modelo católico de ensino superior no Brasil: Padre Leonel Franca e a criação da Pontifícia Universidade Católica - PUC. Revista Internacional de Educação Superior, v. 5, e019014, 12 dez. 2018. Disponível em: https://periodicos.sbu.unicamp.br/ojs/index.php/ riesup/article/view/8653644. Acesso em: 25 maio 2019.

PARRA-SANDOVAL, M. C.; FUCCI BORNACHERA, M.; ROMERO GONZALEZ, A. J. La inserción de la Universidad del Zulia en el proceso de internacionalización de la educación superior. Revista Internacional de Educação Superior, Campinas, SP, v. 5, e019028, 29 jan. 2019. Disponível em: https://periodicos.sbu.unicamp.br/ojs/index.php/riesup/ article/view/8653898. Acesso em: 25 de maio de 2019.

PEREIRA, E. M. A. Internacionalização na universidade contemporânea: uma visão da internacionalização em uma Universidade Pública Paulista. Revista Internacional de Educação Superior, v. 5, e019043, 1 maio 2019. Disponível em:

https://periodicos.sbu.unicamp.br/ojs/index.php/riesup/article/view/8653979.. Acesso em: 25 maio 2019.

PEREIRA, E. M. A. A importância da Reforma de Córdoba para o contexto acadêmico latino-americano: cem anos de contribuição. Revista Internacional de Educação Superior, v. 5, e019037, 16 fev. 2019. Disponível em:

https://periodicos.sbu.unicamp.br/ojs/index.php/riesup/article/view/8653900. Acesso em: 25 maio 2019.

PEREIRA, P.; HEINZLE, M. R. S. A internacionalização das ações de ensino, pesquisa e extensão na Universidade Regional de Blumenau. Revista Internacional de Educação Superior, v. 5, e019038, 19 fev. 2019. Disponível em: https://periodicos.sbu.unicamp.br/ojs/index.php/riesup/article/view/8653902. Acesso em: 25 maio 2019.

RAMOS, M. R. S.; HENZ, C. I.; BOLZAN, D. P. V. Auto(trans)formação permanente e desenvolvimento docente no contexto do PIBID. Revista Internacional de Educação Superior, v. 5, e019003, 2 out. 2018. Disponível em: https://periodicos.sbu.unicamp. br/ojs/index.php/riesup/article/view/8652428. Acesso em: 25 maio 2019.

RODRIGUES, Camila Martins; SANTOS, Gildenir Carolino. A importância e o impacto da Publicação Contínua (PC) nos Periódicos Eletrônicos. Blog PPEC, Campinas, v.1, n.1, jan. 2019. ISSN 2526-9429. Disponível em: http://periodicos.sbu.unicamp.br/blog/index.php/2019/01/15/pc/. Acesso em: 24 maio 2019.

RODRÍGUEZ, M. V.; ANDRADE, S. H. B. DE; PAIVA, F. M. O processo de internacionalização na/da Universidade Federal de Mato Grosso do Sul (UFMS) - Brasil.

Revista Internacional de Educação Superior, v. 5, e019042, 11 mar. 2019. Disponível em: https://periodicos.sbu.unicamp.br/ojs/index.php/riesup/article/view/8653819. Acesso em: 25 maio 2019. 
RUIZ, S. M. DE A.; GEBRAN, R. A. A prática pedagógica colaborativa: pesquisa-ação em um curso de administração. Revista Internacional de Educação Superior, v. 5, e019016, 18 dez. 2018. Disponível em: https://periodicos.sbu.unicamp.br/ojs/index. php/riesup/article/view/8653174. Acesso em: 25 maio 2019.

SANTA ANNA, J. Potencialidades das visitas técnicas na docência universitária: aplicações nas disciplinas de representação da informação. Revista Internacional de Educação Superior, v. 5, e019005, 2 out. 2018. Disponível em: https://periodicos.sbu.unicamp.br/ojs/index.php/riesup/article/view/8653104. Acesso em: 25 maio 2019.

SANTOS, L. A. DOS; MELO, V. Entre Córdoba e Bolonha: o REUNI e a contraditória expansão da universidade brasileira. Revista Internacional de Educação Superior, v. 5, e019015, 13 dez. 2018. Disponível em: https://periodicos.sbu.unicamp.br/ojs/ index.php/riesup/article/view/8653586. Acesso em: 25 maio 2019.

SANTOS, P. K. DOS; MOROSINI, M. C. Internacionalização e educação para a cidadania global: a visão de professores universitários. Revista Internacional de Educação Superior, v. 5, e019040, 24 fev. 2019. Disponível em: https://periodicos.sbu.unicamp.br/ojs/index. php/riesup/article/view/8653913. Acesso em: 25 maio 2019.

SANTO FILHO, José Camilo dos; ALMEIDA, Maria de Lourdes Pinto de; SANTOS, Gildenir Carolino. Revista Internacional de Educação Superior (UNICAMP): o caso da progressão de uma publicação científica. In: CONGRESSO NACIONAL DE EDITORES DE PERIÓDICOS EM EDUCAÇÃO, 1., 2019, Florianópolis. Resumos do... Rio de Janeiro: ANPED, 2019. [No prelo].

SILVA, R.; VAZ, A.; KAVAMURA, E. E. O departamento de desenho da UFPR e o ensino na graduação como definidor da sua trajetória (1974-1993). Revista Internacional de Educação Superior, v. 5, e019004, 2 out. 2018. Disponível em: https://periodicos.sbu.unicamp.br/ojs/index.php/riesup/article/view/8652847. Acesso em: 25 maio 2019.

SOUZA, F. DOS S. Ensino de probabilidade e estatística por meio da análise exploratória de dados e resolução de problemas. Revista Internacional de Educação Superior, v. 5, e019002, 2 out. 2018. Disponível em:

https://periodicos.sbu.unicamp.br/ojs/index.php/riesup/article/view/8652708. Acesso em: 25 maio 2019.

TREVISOL, M. G.; FÁVERO, A. A. As diversas faces da internacionalização: análise comparativa entre duas instituições comunitárias do sul do Brasil. Revista Internacional de Educação Superior, Campinas, SP, v. 5, e019026, 22 jan. 2019. Disponível em: https://periodicos.sbu.unicamp.br/ojs/index.php/riesup/ article/view/8653894. Acesso em: 25 maio 2019. 